\title{
El lugar del ser-hombre en la teología actual
}

\section{JOSE COMBLIN}

Serra Redondo (Paraiba, Brasll)

Hasta hace algunas décadas los tratados de teología estudiaban al hombre dentro del tratado del Dios creador, o sea como uno de los productos de la creación de Dios, después de los ángeles. En este siglo la consideración del hombre recibió una atención mayor y esto se debe, en primer lugar, a la teologia de Karl Rahner. Se puede decir con cierta razón que el centro de la teología de Rahner fue la antropología cristiana. En virtud de su antropologia, Rahner podia en cierto modo proponer la tesis de que la teologia cristiana era antropocéntrica. Este punto de vista fue retomado, ilustrado y profundizado por su discípulo J.B. Metz. El antropocentrismo teológico tuvo una cierta aceptación en el mundo de la teología precisamente en la época del Vaticano II.

En la actualidad, sobre todo en América Latina, la perspectiva es totalmente diferente. Los puntos de partida, los objetivos, la metodología y los temas desarrollados son radicalmente diferentes y pertenecen a otro mundo. No se trata de rechazar de ninguna manera las interesantes consideraciones planteadas por Rahner y sus discipulos. La perspectiva actual no se opone a ésa. Sencillamente ella se está desarrollando en otro mundo en el que no se encontrará con los problemas planteados por Rahner.

\section{Antropología y evangelio}

Rahner fue llevado a poner la antropología en el centro de su relexión teologica no en virtud de una exigencia del evangelio, sino en virtud de dos filosofias entre las que descubrió afinidades: el tomismo y la filosfía existencial. Podemos decir que hoy dia ni el tomismo ni la filosolia existencial constituyen urgencias para nosotros. Hoy día llegamos a la antropología en virtud de una exigencia del evangelio. Pero para aclarar este punto, necesitamos recordar lo que es el evangelio.

\section{a. El evangello hoy}

No podemos partir de los diccionarios ni de la elimologia de la palabra. 
En el Nuevo Testamento el evangelio es una palabra usada por Pablo. ¿Qué es el evangelio para Pablo? Esencialmente, el evangelio de la cruz. El evangelio es la cruz. No es una teoría, una doctrina global. Pues si uno acepta todos los temas y las ideas cristianas, pero no coloca la cruz en su lugar y no le da la importancia única que Pablo descubre en ella, sencillamente no es cristiano. La fe no consiste en el aceptar toda una representación del mundo. Está en el centro que ilumina todo lo demás.

Ahora bien, ¿qué significa la cruz en la mente de Pablo? La cruz es la opción por los medios débiles, la renuncia al poder y la fuerza. La cruz es hacerse semejante a los esclavos, aceptar la condición de servidor, menospreciado, perseguido, martirizado. Si esta opción no está en el centro de la vivencia, Pablo estima que la persona no es cristiana, nada entendió, pasó al lado de la fe, niega el evangelio (por ejemplo, Fil. 3, 18; Gal. 1,6-9; 2,19-21; 3,1; Cor 1,17-25, y, de modo general, la concepción que Pablo tiene de la persona del evangelizador).

¿Qué nos revela el ejemplo de Pablo? ¿Por qué Pablo considera que el evangelio está todo entero en la opción por la cruz? Porque en su tiempo el cristianismo estaba enfrentando por un lado al judaismo dominante y su idea de un Mesías poderoso y triunfante, y, por otro lado, al paganismo griego lleno de orgullo intelectual y cultural. En medio de dos aspiraciones a la fuerza, la potencia y el orgullo, Pablo estima que la suerte del evangelio se juega en la cuestión de la fuerza y la debilidad: el que entiende la cruz, ya lo entendió todo, y el que no entendió la cruz, ciertamente es todavía prisionero del judaísmo o del paganismo griego aunque adopte el 99 por ciento del vocabulario cristiano.

Por lo tanto Pablo nos revela que el evangelio es el choque de la palabra de Dios con una situación histórica muy concreta, única, siempre nueva. Para ser siempre igual a sí mismo el evangelio debe cambiar siempre. El repetir hoy dia verbalmente lo que dice Pablo, ya no es un evangelio. Hoy dia el judalsmo y el paganismo griego han dejado de existir. Nuestra situacion es diferente. Los rivales del evangelio son diferentes. No habrá peor traición al evangelio que la recitación literal de Pablo o de cualquier texto del Nuevo Testamento. El evangelio no está ni en el texto, ni en las ideas, ni en la representación del mundo: está en el llamado a una conversión radical, una inversión de valores; y este llamado se ubica en el lugar de las opciones fundamentales de cada epoca y cada persona. O si queremos decirlo de otra manera, hoy día el discurso de la cruz se ubica en otro lugar.

Los cuatro libros llamados "evangelios" y los demás textos del Nuevo Testamento presentan también el evangelio de Cristo: cada uno es diferente porque está orientado hacia personas y grupos en situaciones diferentes. Siempre será el mismo evangelio. Sin embargo, no existe ninguna formula única, siempre válida del evangelio siempre igual. Sólo existen los inumerables evangelios que los evangelizadores han podido descubrir en cada paso de la evangelización del mundo.

Ahora bien, creemos que la teología hoy dia tiene que partir del evangelio: 
no sencillamente del texto del Nuevo Testamento, ni de una teologia llamada bíblica, sino del evangelio anunciado, proclamado hoy día a los hombres de hoy; ese evangelio que es el núcleo vivo, el centro del sisterna nervioso del cristianismo, el choque inicial que introduce en el conocimiento.

¿Cuál es el evangelio en la actualidad? ¿Cuál será el centro que permita discernir la autenticidad de la inautenticidad de la fe? En América Latina es la opción preferencial por los pobres. Seria muy equivocado comprender esa opción como una decisión puramente humana, una esırategia pastoral libremente elegida por la Iglesia. Al revés; la opción por los pobres no es una opción libre. Es para la Iglesia una opción obligatoria porque es la opción de Dios. Dios es el que asume la defensa de los oprimidos, el que escoge a los marginados y va a buscar lo que estaba perdido, es la fuerza de los débiles y la victoria de los vencidos. Se trata de la realidad de Dios o de la verdad sobre Dios. En la opción por los pobres se juega la autenticidad de la fe en Dios, la verdad sobre Cristo. Es lo equivalente del evangelio de la cruz. de Pablo. El que hace la opción por los pobres es Dios. En esto nuestro Dios es diferente de los dioses de los paganos, en eso Cristo es diferente de los salvadores de los demás sistemas y filosofias.

Por ese camino el evangelio nos lleva a una forma de antropologia. Pero esta antropologia es muy distinta de la de los teólogos de hace unos 20 años. La antropología cristiana que reconocemos no es una explicación de la naturaleza del hombre, no es una respuesta a la pregunta: ¿qué es el hombre? ¿Cuál es la esencia del hombre? Las preguntas sobre las esencias no son preguntas evangélicas. El evangelio responde a una pregunla sobre la acción de Dios: ¿qué hace Dios? Ahora bien, lo que Dios hace es optar por los pobres, elegir a los marginados de este mundo para llevar su creación a su término, recrear a su pueblo, completar sus designios.

En la actualidad, la antropología cristiana es respuesta a la pregunta: ¿qué hace Dios en medio de los hombres? La respuesta es: Dios va a buscar lo que estaba perdido, va en busca de todo lo que la sociedad ha rechazado, todo lo que no sirve: enfermos, débiles, cesantes, pecadores, gente sin patria, sin profesión, sin cultura, sin valor. Dios forma a su pueblo a partir de ellos. La antropología es el anuncio de esa novedad. La antropología cristiana tiene su expresión más acabada en las Bien-aventuranzas.

En ese sentido es necesario reconocer que el evangelio tiene en cierto modo su centro en la humanidad. Pues la verdad de Dios se revela en medio de los hombres: al oplar por los pobres Dios revela lo que es. Algo que sucede en medio de los hombres es revelación de Dios.

\section{b. La novedad del evangelio}

El evangelio no trae algo nuevo cuantitativamente, sino cualitativamente. El evangelio de la cruz es escándalo para los judios y locura para los griegos. Es algo nuevo en el sentido de que no cabe dentro de la racionalidad o la normalidad de lo establecido. Es algo que no se integra en lo preexistente, algo que perturba y desintegra todo lo existente y obliga a cambiarlo todo. 
No es que la cruz no existiera para los griegos y los judios, existia entre ellos, pero ellos no querian verla. Ella no tenía sentido para ellos; para ellos todo lo débil era una ofensa, algo inaceptable. La novedad del evangelio es que pone en el centro lo que los demás rechazaban. Nuevo quiere decir lo contrario, la inversión de lo establecido.

La antropología cristiana consiste en algo nuevo. No tiene por finalidad la construcción de una representación completa ni global del hombre o de la humanidad. Siendo esencialmente "pobre," el cristianismo no puede tener la pretension de dirigir la cultura ni de ofrecer a una sociedad una imagen completa. Jesús de Nazareth no tenia ninguna visión intelectual de la humanidad para proponer; y iqué es lo que permitiría a los cristianos hacerlo si El no lo hizo?

La antropología cristiana trae algo nuevo que sólo ella podía traer: ella hace entrar a los pobres. En América Latina se puede decir que el primer gran documento de la antropología cristiana es la proclamación del Papa Paulo III de que los indios eran también hombres. Los invasores trataban de ignorar que los indios eran hombres, porque si lo admitian, no podian actuar como de hecho actuaban, Paulo III retiró el velo que cubría la realidad y obligo a reconocer que los indios eran hombres. Su antropologia no consistía en explicar la esencia del hombre; las filosofias lo hacen. Pero hay algo que los filosofos no hacen: decir en esa circunstancia que los indios eran hombres. Decirlo en el siglo XX no cuesta o cuesta menos. Decirlo en el siglo XVl significb para muchos la muerte, el exilio, la difamación.

En la actualidad, ¿cuál es la novedad antropológica del evangelio? Es decirles a los pobres del Tercer Mundo que ellos también son hombres, porque ellos no se atreven a pensarlo, tienen miedo, no tienen esperanza. El evangelio no dice lo que es el hombre, sino más bien quién es hombre.

\section{c. Lo concreto del evangello}

Las filosolias hablan del hombre en general a los hombres en general. No atacan ni perturban a nadie. El evangelio habla a personas concretas. Una doctrina general, un conjunto de ideas, no puede ser un evangelio, por que no es buena nueva para nadie. Lo que es para todos no es para nadie. El evangelio consiste en decirles algo bueno a ciertas personas escogidas: a los pobres.

Decirles a los ricos o a un grupo de estudiantes, de alumnos, de intelectuales interesados por la filosofía y la antropologia que los hombres son los pobres, no es un evangelio. Pues el evangelio consiste en ir a decirles a los mismos pobres que ellos son realmente hombres con toda la dignidad y los derechos de los hombres; decirselo de tal modo que lo entiendan y lo vivan y realmente resuciten de su no-humanidad, esto sí es evangelio. Esa es la antropología cristiana. Por eso la antropología cristiana consiste en ubicarse muy bien, exactamente en la línea de Cristo. Porque si la teologia está basada en el evangelio, ella no es pura teoria. Ella es práctica. Hacer teología no es elaborar un sistema de ideas y representaciones. Este aspecto existirá, pero subordinado a lo esencial. Hacer teologia es una práclica, a intervenir en medio 
de los hombres concretos, tomando partido en lavor de unos y en contra de otros. Por eso, la antropologia es un acto concreto de llamar hombres a los pobres y oprimidos, no en general, sino a aquellos oprimidos muy concretos que all estan; asi como los misioneros del siglo XVI les hablaron a los indios.

Por lo tanto, la antropologia cristiana no es una doctrina sobre los hombres o sobre la esencia humana, sino una interpelación dirigida a los hombres, o sea, $a$ determinados hombres. Pues la antropologia de Jesús no consistio en una doctrina sobre el hombre, realidad que falta totalmente en el Nuevo Testamento. No porque Jesús se desinteresara de los hombres, sino más bien al revés. La antropologia de Jesús estaba en su manera de ubicarse entre los hombres de su tiempo; ella era opción y acluación concreta, toma de posición social, definicion de una determinada red de relaciones sociales.

De todo lo anterior resulta que en nuestros dias el evangelio es antropología. Pero no lo es en el sentido de una doctrina sobre el hombre en general: es el anuncio de que son hombres a los inumerables individuos rechazados y expulsados fuera de la humanidad que se contempla a si misma; el anuncio hecho a las razas oprimidas, a los grupos sociales oprimidos, el anuncio de una inversión de la presente situación.

\section{Antropología y sabiduría}

La teología se basa en el evangelio y recibe su orientación fundamental del evangelio. Los momentos históricos en los que la teologia aceptó las estructuras y las metodologias de una filosofia como en los siglos XIV y XV fueron momentos de decadencia. El mismo Tomás de Aquino no se sometc a la ordenación de la teologia por Aristóteles, sino que lo subordina al evangelio; muchos de sus discipulos no pudieron descubrir la forma como él lo hacía.

Sin embargo, la teologia no es el evangelio ni la evangelización, pues el evangelio y la evangelización son obra de todos los cristianos. La teología ocupa una posición especííca dentro del evangelio y la evangelización. Su lugar es el de la sabiduria.

¿Qué tiene el teólogo que no tiene el cristiano sencillo? Nada de lo que se refiere al mismo evangelio. No tiene un conocimiento superior del mismo evangelio. El teólogo es un técnico que conoce las doctrinas, filosofías, ideologias humanas en medio de las cuales se mueve el pueblo cristiano; to específico del teoblogo es su conocimiento superior de la realidad del mundo humano que lo cerca. No tiene capacidad para juzgar la fe, sino para juzgar las doctrinas, ideologias, filosofias en nombre de la fe.

Porque conoce mejor la complejidad del mundo social y sus ideas, el teólogo puede ayudar a sus hermanos a caminar en medio de este mundo sin dejarse engañar o ilusionar por él. La teologia no es evangelio, sino sabiduría. Su tarea es el discernimiento. Ella compara el evangelio con el mundo humano en que vive la Iglesia de Dios.

\section{g. El discernimiento}

Hay dos discernimientos, uno de la fe y otro de la teología. El evangelio 
practica el discernimiento fundamental: entre los escribas, fariseos y otros falsos pastores que no entienden, no pueden entender y a los que Jesús niega la explicación para que no entiendan por un lado, y, por otro lado, los sencillos, los pobres, los humildes a los que Jesús reserva sus ensehanzas. Este discernimiento no es tarea del tcólogo. No es él la persona más capacitada para hacerlo; lo hacen los mismos pobres y sencillos y el teólogo se remite a ellos.

Pero hay otro discernimiento: discernir entre las doctrinas, ideologias, modos de conducta, prácticas que se presentan en el mundo. No se trata de hacer un discernimiento en todo eso entre lo verdadero y lo falso, pues no se trata de verdad y error, sino de algo anterior a Cristo, los primeros pasos de la humanidad en los cuales se mezclan verdad y error. El objeto del discernimiento teológico es éste: ¿cómo practicar el diálogo con todo ese mundo? ¿Cómo entrar en contacto, como expresar el evangelio, cómo encontrar elementos que puedan ayudar y descubrir los elementos que van a perjudicar?

Pues los cristianos no viven ajenos al mundo; no tiene lengua propia y hablan las lenguas de los demás hombres. No tienen manos propias, ni cultura propia, sino que usan la cultura que los rodea. El discernimiento teologico ayuda a conocer mejor ese mundo y a saber aprovecharlo mejor.

\section{b. La convivencia con el pecado y el error}

Todavia hay cristianos que creen que su misión consiste en eliminar el pecado y el error del mundo. Son herederos de la historia de las cruzadas, de la guerra milenaria contra el Islam, de la persecución a los herejes, de las guerras de religión y la inquisición. Sin embargo, el ejemplo de Jesús muestra que el problema cristiano es la convivencia con el pecado y el error. No se trata de vivir en un mundo preservado del pecado y del error, sino más bien, al contrario, dentro de un mundo de pecado y de error.

Jesús afirma explícitamente que no se trata de hacer la separación entre los buenos y los malos; los discípulos tendrán que vivir con los pecadores y convivir con los errores. El problema es icomo convivir con el mal sin caer en el mal? ¿Como convivir con el error sin caer en el error? En esto consiste la sabiduria teológica. Es una parte de la sabiduria política. Pues esta última consiste en el arte de vivir en el mundo de los hombres que existen y no en un mundo teórico o abstracto. La teologia puede ayudar a los cristianos a vivir el evangelio en este mundo complejo, en medio de los pecadores y herejes, en medio de las doctrinas y las prácticas más diversas.

En la actualidad, las doctrinas que componen el ambiente intelectual son antropologías. En otros tiempos los hombres ponian su concepción de la misma humanidad en sus ideas sobre los dioses y la antropología estaba en la teología en sentido estricto. Hoy día es al reves; los hombres ponen sus teologias en sus antropologias. La fachada es la de un conflicto de antropologias. Por supuesto detrás de la fachada de las antropologías la oposición es más profunda, más completa también.

Puesto que estamos en un mundo de conflictos entre antropologias, no podemos dejar de aplicar a ese mundo el discernimiento teológico. No se trata 
de affadir a las antropologias vigentes otra más. No se trata de construir una antropologia cristiana que fuera semejante a ellas. Esto nos obligaría a luchar para destruir las demás antropologías y ocupar su lugar en el mundo. Sería volver al sueño de las universidades medievales. Sería subordinar el evangelio a plano de conquista del mundo, conquista cultural que supone también una conquista material. Por lo tanto, la teologia cristiana no tiene por tarea la construcción de una antropología como edificio cultural, como doctrina completa.

Una antropologia cristiana busca la manera de proclamar y vivir el evangelio en medio de las antropologías contemporáneas, tratando de traducirlo para que sea comprensible, de ubicarlo en medio del choque de las aspiraciones humanas, preservándolo de la ilusión y la corrupción, abriéndole caminos para que pueda convivir, penetrar, convencer y cambiar.

En el pasado hubo una teologia polémica que tomó por misión el detectar los errores, identificarlos, fustigarlos, condenarlos y crear en los cristianos un tal terror hacia ellos que nunca se atrevieran a acercarse. Este fue el papel de la mayor parte de la teologia del siglo XIX. ¿Qué es lo que queda de ella? ¿Acaso logró destruir los errores o sistemas que tanto combatía? Al linal no aumento la tentación, añadiéndole el prestigio de lo desconocido, de lo misterioso?

\section{c. Las antropologias contemporáneas}

América Latina está casi completamente integrada dentro de la sociedad occidental. Esta es el resultado de una larga evolución. En este momento ella presenta un mensaje fundamental bastante unificado gracias a las técnicas de comunicación que transiten inmediatamente los modelos de vida nacidos en los centros. Hay un modo de vivir cuya publicidad está hecha por la televisión, los supermercados y el conjunto de la propaganda comercial. El modelo se puede caracterizar por tres palabras: individualismo, narcisismo, consumismo.

Individualismo, porque a cada instante se predica que la referencia suprema es el individuo y la única norma de la acción la realización del individuo. El individualismo es una antropología antigua. Nació en el Renacimiento, pero sólo en el siglo XX logró difundirse en la masa de los pobres, unificando asi el etos de los pueblos occidentales. En este siglo el indivualismo ha logrado destruir casi completamente todo lo que era fidelidad a un compromiso, solidaridad, hospitalidad y gratuidad en las relaciones sociales. Logró destruir la familia, la vecindad, la corporación y la solidaridad de los trabajadores y la misma religión concebida como compromiso con Dios.

Narcisismo, porque la cultura dominante lleva al individuo a contemplarse incesantemente, al hacer de sí mismo la norma de todo. El individuo está estimulado para contemplar sus necesidades, sus deseos, sus preferencias, sus opiniones. Su subjetividad se hace la norma radical de su conducta. Lo que vale es su satisfaccion, su bienestar, su tranquilidad, su placer.

Consumismo, porque el modelo enseña que la satisfacción, el gozo y el placer supremo se logran mediante el consumo de objetos exteriores. El 
hombre deja de buscar en si mismo o en sus actividades inmanentes, incluso en sus actividades exteriores la fuente de su satisfacción. No será ni la familia, ni el trabajo, ni la cultura ni ninguna forma de actividad, sino el uso de bienes que se puede comprar. Soblo lo que se puede comprar proporciona una satisfacción.

Dentro de la civilización occidental sobreviven islas de núcleos humanos que viven otra cosa. Pero la ideología dominante es ésta. De modo particular la antropologia que los centros principales divulgan en las periferias en ésa, mucho más que la antropología de las islas.

Una antropologia cristiana permitirá entender mejor cuál es la antropología del mundo occidental y cómo se puede convivir con ella, o sea, ser cristiano en un mundo impregnado por sus ideales y practicando ese modo de vivir. Permite un discernimiento de lo que es válido y bueno y lo que es destructor o ilusorio en el modo de vivir occidental.

Lo que interesa a la antropologia cristiana no son las teorías o las filosofias que representan sólo la visión de si mismas; la visión que tienen algunos intelectuales o las legitimaciones que las sociedades dan de si mismas. Objeto de la teología son más bien las antropologías vividas realmente por los pueblos y trasmitidas por medios habitualmente informales.

Frente a la antropología occidental se levanta la antropología marxista o comunista como principal desafiante. En la mayoria de los paises latinoamericanos ella se presenta todavía como teoría pura, no como modelo de vida realmente vivido. El socialismo real no es muy conocido, ni la antropologia incluida en el socialismo real. Cada país puede siempre mantener la esperanza de que será capaz de crear otro socialismo real. Y ciertamente no se puede excluir la posibilidad de que puedan nacer nuevos modelos. Sería negar la misma historia la cual muestra que todo cambia y todo se transforma. El problema del marxismo merece una atención especial, sobre todo después de la Instrucción de la Congregación de la Doctrina de la Fe del 6 de agosto de 1984. Por eso no trataremos aquí los problemas especificos suscitados por el marxismo.

Hay un elemento común en casi todo el Tercer Mundo y es las naciones latinoamericanas en particular: la consolidación de modelos autoritarios de sociedad, tanto los modelos militares o para-militares de derecha como los movimientos nacidos de las guerrillas y que conservan desde sus origenes muchas características militares. El elemento común es el pesimismo en relación a las masas populares y la afirmación de la autoridad de los intelectuales. Los que mandan son los propietarios de la ideologia, los hombres que poseen la llamada "ciencia," es decir, la ideología oficial. La participación efectiva de las masas populares en la definición de los objetivos es minima. La doctrina de la seguridad nacional la niega radicalmente y sus postulados aún desempeñan un papel importante en casi todo el continente.

Frente al pesimismo oficial, la antropología cristiana está llamada a afirmar el valor del hombre común, pobre, sin instruccion, el valor de su juicio, sus aspiraicones, sus criterios y su voluntad politica. 
Una antropologia cristiana no consiste en una doctrina sobre el hombre. Las doctrinas antropológicas sirven casi exclusivamente para fines publicilarios; son como los programas de los políticos. La antropologia está en las opciones reales. Estuvo y todavia está en la educación popular, en los movimiencos de educación de base y también de simple alfabetización, en la organización de los pobres, en la formacion de las comunidades.

La antropologia está ligada a la eclesiología. Pues icómo podria la lglesia promover realmente a los pobres si mantuviera una estructura verticalista en su organización interna? Las mismas comunidades de base son reveladoras de la antropología real de la Iglesia católica.

No existe ninguna probabilidad histórica de que una eventual antropologia "cristiana" pudiera vencer y ocupar el lugar que ocupan actualmente las dos antropologías que están en competencia en el mundo actual. El problema de los cristianos está en la convivencia con ellas. ¿En qué forma podemos anunciar realmente la opción preferencial por los pobres en un mundo que la rechaza como absurda y ni siquiera puede llegar a entenderla?

Seria muy fácil elaborar una exposición doctrinal de los bellos temas cristianos sobre la humanidad ideal. Fácil y vano. Nuestros contemporáneos no están muy dispuestos a escuchar nuestros discursos. El problema antropológico concreto es, ¿de qué modo nos relacionamos con los dos grandes sistemas antropológicos actuales? ¿Cuál es la posición que tenemos en medio de o frente a ellos? La doctrina antropológica no se separa de la práctica pastoral. Al revés ella se encuentra dentro de la misma práctica pastoral.

\section{Antropología y oración}

En la antigua teologia escolástica el hombre se definia en primer lugar por el pensamiento o el intelecto. La teologla conservaba asi el mensaje de la filosofia griega mucho más que el de la Biblia. De todos modos desde hace varias generaciones esa antropologia griega es completamente incomprensible en el mundo moderno. Siempre fue el ideal de un grupo infimo de filosofos. Hace tiempo que los filósofos ya no le entienden siquiera. Ya nadie puede comprender que el valor del ser humano estaria en su pensamiento. Dejemos eso de lado.

El pensamiento está presente en nuestros contemporáneos en la forma de conciencia. La conciencia existe. La cuestión es, ¿cuál es el valor de la conciencia? ¿De qué sirve la conciencia? ¿Qué papel ocupa en la existencia humana?

En la conciencia está Dios. ¿Cuál es el papel que desempeña la conciencia de Dios en la vida humana? La conciencia de Dios, en lo concreto, es la oracion. En el occidente desde hace muchas generaciones, en el mundo intelectual, Dios ha desaparecido de la conciencia. Aunque se acepte y reconozca como creador del mundo y sefhor del universo, Dios no pasa de la condición de objeto en la representación del mundo. Como los reyes constitucionales, Dios está en el lugar de honor del edifício del mundo, pero no ocupa ningun lugar en la vida consciente. El hombre moderno no conoce la oracion y no le reconoce ningún significado. La oración le es ajena. Aún muchos cristianos ya no le 
encuentran sentido. Más aún, a menudo los mismos religiosos le son fieles más bien por obediencia, por fidelidad a un compromiso asumido que por necesidad; oran por obligación más bien que por tendencia espontánea. Aqui hay un problema antropológico fundamental.

\section{a. El rechezo de la oración y sus razones}

En el individualismo moderno la conciencia individual es la referencia suprema y la norma última de la existencia y los valores. La conciencia se encierra en su autonomia y se toma a sí misma como su razón de ser y su finalidad. Ya no hay nada que valga más allá de la conciencia. Y la conciencia es la forma de afirmación del yo. La norma es el saber por sí mismo, el juzgar por sí mismo, el decidir por sí mismo. La realización plena del yo es la finalidad. Siempre inseguro, insatisfecho, inquieto por si mismo, el yo siente la necesidad de sentirse siempre más, de percibir que está realmente viviendo. Tiene la necesidad de multiplicar los actos por los que se afirma. Cada cual quiere ser "yo" lo más posible.

El hombre moderno ha desarrollado inmensamente su preocupacion por su conciencia. Vive observando, auscultando su conciencia; observando todos los movimientos de su "yo," afectado por cualquier cambio de humor. Basta con recordar la importancia de las consultas psicologicas en las clases medias y superiores de la sociedad occidental.

La atención dada a la conciencia no llevo, sin embargo, a un desarrollo de la oración. Al revés. Hasta cierto punto se puede decir que al encerrarse en su "yo"' psicologico el hombre moderno se hizo incapaz de oración. Es el prisionero de sus estados psicológicos, no es capaz de escuchar a otro, ni de recibir otra orientación. Es significativo que la misma época que conoce un desarrollo fantástico de la psicologia tiene que constatar una creciente incapacidad de comunicación entre los individuos. Cada cual está de tal modo absorto en su "yo" psicológico que no puede prestar atención a otros.

En cuanto a los marxistas, no hay ninguna señal de que puedan dar a la oración ningún valor positivo. No sólo no la cultivan, sino que a menudo la combaten. Para muchos la oración será una expresión típica de la alienación humana.

No es que los partidos comunistas y asimilados no den importancia a la conciencia aunque aparentemente el materialismo historico y el materialismo dialéctico tienden a menospreciar los hechos de conciencia. Uno podría pensar que los partidos no darían mucho valor a la conciencia para dedicar su atención a los hechos económicos. En la práctica sucede todo lo contrario. Sus actividades los alejan mucho de la economia y se desarrollan casi exclusivamente al nivel de la conciencia. Pero la actividad de la conciencia consiste ahora en la asimilación y las diversas expresiones de la ideologia. Fundamental es el conocimiento del marxismo como sistema del pensamiento y la difusion de la ideologia. El esfuerzo se concentra en el paso de la conciencia alienada hacia la conciencia verdadera. La conciencia alienada es la que no se identificó con la ideologia. La conciencia verdadera es la que logro asimilar perfectamente la 
ideologia, sus criterios, sus conceptos y su metodología. Pues en los partidos lo que vale, lo que es referencia última, es la perfecta identificación con la ideologia. Solo el que puede mostrar que domina perfectamente la ideología y es capaz de aplicarla con soltura a cada momento tiene la posibilidad de alcanzar una posición importante.

En esa forma la conciencia "revolucionaria" encierra la conciencia individual en la ideología. Su forma más perfecta es la situación del individuo que ya no piensa más por si mismo como individuo y en el que piensa la ideología. No es el que piensa personalmente, sino el que expresa perfectamente el pensamiento del marxismo. La conciencia individual se apaga para dejar todo el espacio a la conciencia de la ideología.

Esa actitud de la conciencia no es exclusiva de los partidos comunistas y similares. Ella se encuentra también en el integrismo católico, y sabemos que el integrismo fue la actitud católica dominante en la segunda mitad del siglo pasado, alcanzó su momento culminante bajo el pontificado de Pio X y sobrevive en muchos católicos hasta Vaticano II. En el integrismo también la conciencia individual desaparece para revestirse de una conciencia colectiva. El católico integrista se identifica con lo que piensa ser el catolicismo, deja de pensar por si mismo, asimila un sistema de referencia que aplica a cada momento. Nunca piensa, sino que hace que una máquina de pensar colectiva se exprese por medio de él. Cree que así expresa una realidad eclesial. También el integrismo se hace incapaz de oración. Su oración es un ejercicio de obediencia y de sumisión de la conciencia, es el ejercicio por el cual el individuo apaga to que le queda de personalidad y se identifica con la conciencia colectiva. Ejerce todas las formas de la oración, pero no ora; no sale de su conciencia y esta se reduce a la asimilación de un sistema cultural.

Mirando por todos los lados, tenemos que constatar el hecho de que la oración ya no pertenece a lo esencial de la vida humana para la mayoria de nuestros contemporáneos. Muchos de ellos no llegan siquiera a comprender que en las generaciones anteriores la oración haya podido tener tanto valor. Lo interpretan como una prueba de la alienación universal de la humanidad hasta nuestros dias.

\section{b. El sentido de la oraclón en la antropología}

En primer lugar tenemos que descartar las deformaciones de la oración que serian precisamente las penetraciones de la anti-oración en la misma oración. No es oración la meditación sobre sí mismo. Tampoco es oración la pura repetición interior o exterior de conceptos religiosos. Uno puede, como un actor, leer un texto con emoción, con expresión sin que esa expresion sea oración. Uno puede prestar su conciencia a la recitación de textos o ideas religiosas. Un incrédulo que es buen actor podrá expresar muy bien un texto de oración sin hacer nada de oración. Uno puede asumir el papel de oración. Pero hacer el papel de la oración es lo contrario de la oración.

Como todos saben, en la oración las palabras, los gestos, las expresiones no valen por si mismas. Los elementos "conscientes" no son la oración, son lo 
contrario. Sirven para preparar el silencio en el cual está la oración misma. Si las palabras retienen la atención, ellas impiden la oración. La oración está más allá de la conciencia. Justamente por eso ella enseña el verdadero sentido y el valor de la conciencia. Esta no vale en sí misma. No es un fin. En la medida en que el hombre se preocupa por su conciencia y presta atención a su conciencia, en realidad él se destruye a si mismo y se aparta del verdadero ser humano. Si la oración 〔uera actividad de la conciencia, ella llevaria de hecho a una alienación.

Por la oración, la persona sale de los limites de su "yo" individual para situarse en la verdadera realidad. No importa el nombre de "Dios." Los mismos nombres y las palabras que hablan de religión, todavía encierran en la conciencia y el "yo." Ahora bien, por la oración el yo se desprende de sí mismo, se apaga y entra en la realidad del ser.

La oración es el escuchar en primer lugar; es la actitud del que no sabe y sabe que no sabe y se pone a hacer el silencio en si mismo y de sí mismo para escuchar. Deja que todo el universo le hable; escucha el clamor del mundo y se apaga para que el clamor del mundo hable en si mismo. Pues la oración no es un diálogo entre el "yo" mío y el "yo" de Dios, sino entre el clamor del mundo y la presencia inefable, inalcanzable. El clamor del mundo es la voz profunda de la humanidad, esa voz de la que el mismo mundo no toma conciencia. Los Salmos, por ejemplo, son una expresión del clamor. Ahora bien, en los Salmos hay un "yo" que clama y ora: ese "yo" individual, ni el "yo" de David o del autor del Salmo. El "yo" que ora en los Salmos es la misma humanidad más allá de su conciencia, en la fuente de su existencia terrestre. En la oracion, el cristianismo - y todo hombre religioso- se retira para que en lugar de su "yo" hable el clamor del mundo; su conciencia se transforma en el lugar del clamor del mundo. La conciencia escucha para, en seguida, abrir el camino al clamor del mundo que se escucha. Ella desaparece como conciencia individual para hacer la voz de la humanidad.

El clamor de la humanidad es expresión de dolor y al mismo liempo de denuncia y prolesta. Es un llamado y al mismo tiempo expresión de fe y confianza en el destinalario de la súplica. Pues la súplica ya conliene y expresa la respuesta. El Dios, o sea, el Desconocido, el Presente-Ausente, que se invoca es también el que se oculta detrás de la invocación. Dios es el que se invoca y el que invoca. En la invocación el hombre abre espacio a Dios para que sea Dios el que invoque. Pues en Crislo el mismo Dios asume el clamor de su pueblo. La fe y la esperanza expresan precisamente la presencia escondida y silenciosa de Dios en el mismo grito que lo llama.

Por eso, la oración es también el espacio de silencio que se abre para que Dios hable. La función de la conciencia consiste en preparar ese espacio para que Dios hable. El ser humano se hace así escucha de la palabra de Dios y la palabra de Dios está en el mismo silencio.

Por consiguiente, el significado de la conciencia no está en la misma conciencia. En la misma conciencia están las palabras, los conceptos, los sentimientos, los impulsos, las inclinaciones y el mismo "yo" consciente de sí. To- 
do aquello es superficial. Si le prestamos atención, todo eso nos lleva a vivir en lo ficticio, en un mundo de representaciones al lado del mundo real. La conciencia se transforma entonces en un mundo paralelo, que no deja de ser sin consistencia aunque sea llenado de "valores espirituales," "cultura," elc. El que se instala en el mundo de ficciones. Aqui valen todas las críticas de los grandes maestros de la "sospecha" (Freud, Marx, Nielzsche, etc.).

Pero la oración es justamente el nivel de realidad que va más allá de la conciencia para situarnos en la misma realidad. La conciencia nos sirve como instrumento para poder penetrar más allá de ella. En ella hay un dinamismo que nos permite liberarnos de ella. Si la conciencia nos sirviera para vivir al nivel de nuestro "yo," ella nos apartaria de la realidad del mundo, para encerrarnos en un pequeño mundo aislado artificialmente y hecho fetiche: el "yo."

Desde los orígenes de la humanidad, lo que sabemos de las civilizaciones es que los hombres han buscado los caminos de la oracion. Si contemplamos lo que todavia sobrevive de la humanidad antigua anterior a la cultura modern?, entre los campesinos o artesanos, cazadores o pescadores tradicionales, podemos constatar que su existencia se desarrolla en la práctica y en la búsqueda de una oración permanente. El campesino en su tierra deja que el universo presente en él invoque a Dios (cualquiera que sean las palabras que lo representan, las cuales nunca han de ser tomadas como algo más que un puro canino).

Con la modernidad y la nueva civilizacion burguesa se destruyo la oración. El ser humano se buscó en dos niveles, por lo demás radicalmente separados: el nivel de la producción de objetos en el que el objeto es lo que vale y no la persona que lo produce, y el nivel de "yo" consciente que es el del pensamiento como conciencia del "yo." Al nivel de la producción, se destruye la relación de amistad y convivencia entre el hombre y el universo. Lo que importa, es la producción y el trabajador es reducido al papel de la máquina. El objeto y el consumo del objeto se hacen los objetivos de la vida. El "yo" nace como reducto del individuo rechazado del mundo del trabajo. Separado del mundo material, el "yo" de la conciencia se refugia y se concentra en sí mismo: su preocupación consiste en manifestar su existencia, hacerse siempre más sensible para darse la seguridad de que todavia realmente existe. Se ha destruido el lazo entre el hombre y la realidad. Y la oración que lo mantenia todo unido desaparecio.

La oración no nos aparta del trabajo y de la actividad en el mundo. Al contrario. Puesto que ella no es actividad de la conciencia, sino presencia en la misma realidad del universo, ella sola puede humanizar el trabajo y toda la actividad material. Ella sola puede reeducar a los hombres para que el trabajo deje de ser la gran alienación del trabajador en el objeto de su trabajo y hacer del trabajo la comunión con el mismo movimiento del universo, o sea, la cooperación con el Dios creador de la que habla el Papa Juan Pablo II en la encíclica Laborem Exercens.

La oración nos salva también de la permanente mistificación que es la afirmación del "yo" consciente, la permanente mistificación que es la misma 
conciencia. La cultura burguesa está exaltando de modo supremo esa conciencia, mientras los socialismos reales la reemplazan por la ficción de una conciencia colectiva. Sólo regresando a la oración profunda podremos salvarnos de ese reino de la futilidad, de lo superficial, de ese imperio de los discursos vacios que ha creado la modernidad.

Por supuesto, las antropologias modernas ignoran la oración. Ya no la encuentran en el pseudo-mundo actual, dado que ella ha sido expulsado sistemáticamente, y lo que todavía permanece es víctima de un tabú, es un asunto del que no se puede hablar.

\section{c. Oración y acción}

La oración no se opone a la acción. Al revés ella sólo puede existir en la acción. Ora el labora: orar y trabajar son las dos vertientes de la existencia humana. Ellas componen la antropologia cristiana. La acción sin oración se transforma en pura operación objeto como el trabajo de los esclavos; es un trabajo de alienación en el que el ser humano no se expresa, ni vive. La oración sin trabajo se expone a caer en la pura ilusión de la conciencia pura. El trabajo es lo que le da contenido y valor de realidad.

En la oración y por la oración el trabajo y toda actividad humana se viven humanamente: es decir, como dones de y respuestas a Dios, como emergencias de la energia vital de Dios y como expresion del clamor de los pobres y abandonados; como grito del sufrimiento humano y como respuesta de comprension, amor y ternura por el sufrimiento humano.

Sin oración el trabajo cae bajo el dominjo de señores, como personas o como estructuras impersonales. El trabajo cae bajo la dominación de las exigencias e imperativos técnicos y económicos. Queda vacio de contenido humano, rigido, inflexible, movido por consideraciones puramente abstractas. Con la oración el mismo trabajo entra en la órbita de las realidades que el hombre puede cambiar, humanizar, mejorar.

Sin oración el trabajo y toda la actividad humana caen bajo los criterios de los objetos producidos y del consumo de los objetos. Deja de valer en sí mismo; produce obras puramente funcionales, hechas para el consumo y no para la amistad, la convivencia. La oración es lo que permite subordinar el trabajo al mundo real, es decir, el mundo de las relaciones reales entre los hombres y con Dios.

El hombre moderno acabo finalmente con rencor y resentimiento hacia el trabajo y volvió a considerarlo como esclavitud pura. $O$, en el caso de los que lo dominan y dominan a los trabajadores, el trabajo se transforma en una droga que inspira orgullo, voluntad de poder, menosprecio a los débiles.

Lo que impide la oración es que los mismos cristianos acabaron pensando que la oración estaba en las palabras, en las recitaciones, en un discurso de formas tipicas; todo lo contrario de la oración cristiana y verdadera. Muchos aceptaron implicita o explicitamente los rechazos de la cultura moderna. 


\section{Lo concreto de la antropología cristiana}

¿Como se unen oración y acción? La antropologia cristiana no tiene ni pretende ofrecer una doctrina al respecto. Ella ofrece algo más que una doctrina, es decir, la realización concreta de personas concretas que viven esa unión. Son modelos incompletos, imperfectos, pero suficientes para que quede claro lo que se quiere decir.

La antropología cristiana es la que viven por un lado las comunidades cristianas, y, por otro lado, los misioneros cristianos, prototipos de los indiviJuos en la Iglesia. Comunidades y misioneros son los dos modelos que ofrece el Nuevo Testamento. Fueron preparados por el pueblo de Israel y los profetas y sabios. Son renovados constantemente por la acción del Espirilu Santo en la historia.

Más allá de todas las explicaciones teóricas, el mensaje cristiano sobre el hombre está en las personas concretas con toda la diversidad de los cristianos ejemplares que hubo en la historia. Ninguna explicación teórica podria agotar el contenido de las vidas realmente vividas. Por eso, la Iglesia conserva el recuerdo y la memoria de sus "santos," no sólo de los canonizados, puesto que la canonización limita mucho cuantitativa y cualitativamente a los santos. En la vida celebrada y conservada de sus representantes, de los misioneros que dieron su dinamismo a las comunidades, la lglesia transmite una antropologia. La teologia será mediadora entre esas vidas vividas en el pasado y los tiempos presentes para que el mensaje de esas vidas pueda ser entendido en el mundo presente.

Lo concreto de la antropologia no suprime el valor de ciertas explicaciones leóricas, pero relativiza mucho su importancia. Así se explica por qué hasta una época muy reciente la teologia no tenia antropologia desarrollada. Los cristianos no la necesitaban, puesto que tenian la memoria de los ejemplos de los santos.

Hoy día, algunos que buscan una antropologia cristiana explícita y expositiva podrian quedar engañados por la lectura de lo que ofrecen los tratados de teologia. Estos no representan realmente la antropologia cristiana. Solo recuerdan algunos conceptos que fueron discutidos entre teologos en el pasado o provocaron intervenciones del magisterio. Con eso no se hace una antropologia. La verdadera antropologia cristiana si que existe. Solo le falta una cierta sistematización.

A menudo los grandes conductores de la Iglesia han sido fundadores de sociedad monásticas o religiosas. Su memoria se guarda en la institución que fundaron. A veces estas tienden a considerarlos como su propiedad exclusiva. El pueblo cristiano ve en ellos el modelo de los religiosos y no se reconoce en ellos porque han sido monopolizados. Por eso, queda huerfano de modelos cristianos concretos. Sin embargo, allá están. Los teólogos no deberían escribir biografias de los santos para exaltar los institutos que fundaron, sino más bien para buscar en ellos una iluminación para la Iglesia entera.

Cada uno de los santos ha podido lograr una manera de trabajar en este mundo y vivir ese trabajo en Dios. Cada uno tuvo su estilo de oración. Hoy día 
las condiciones son diferentes, pero el desafio es el mismo. El ejemplo de los antecesores es un desafio para nosotros hoy. Si ellos han podido solucionar el problema del ser humano en su tiempo, también podemos hacerlo.

Pero la consecuencia de esto es que la antropología para el tiempo presente no existe previamente. Se está haciendo. Se podrá hacer de ella una buena teoria después. Por el momento estamos actuando con fragmentos de luz, elementos de teoria. Cuando la teoria esté completa será la prueba de que la fase de creatividad e invención ya ha pasado y comienza la fase de la fijación y burocratización.

En las comunidades y los nuevos ministros del tiempo presente se encuentra ya el modelo de hombre que presenta la figura del ser humano y de la humanidad tales como Dios quiere que sean en nuestro tiempo. 